\title{
Lepadarq
}

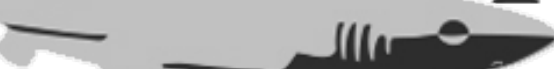

\section{COMUNIDADES DE PESCA: PESSOAS, MATERIAIS, LUGARES E PEIXES}

FISHING COMMUNITIES: PEOPLE, THINGS, PLACES AND FISHES

Organizadores:

Caroline Borges

Lucas Antonio da Silva

Como citar este texto:

BORGES, Caroline; SILVA, Lucas Antonio da. Comunidades de pesca: pessoas, materiais, lugares e peixes. In: Cadernos do Lepaarq, v. XVI, n.32., p. 27-29, Jul-Dez. 2019. 


\section{COMUNIDADES DE PESCA: PESSOAS, MATERIAIS, LUGARES E PEIXES}

A reflexão que deu origem a este dossiê parte da constatação, fundada em nossa trajetória de pesquisa, da pouca visibilidade dada as comunidades pescadoras, suas práticas de pesca e seu mundo material nos estudos recentes da arqueologia brasileira. Para tentar promover um melhor contato e trocas entre diferentes pesquisadoras e pesquisadores, propusemos na reunião da SAB-Regional Sul de 2018, que ocorreu em Curitiba/PR entre 8 e 11 de outubro, um simpósio sobre a arqueologia da pesca chamado "Pesca e arqueologia: contextos, materiais, lugares, peixes e comunidades". Durante este simpósio foram apresentados dezesseis trabalhos com os mais variados temas envolvendo a pesca. Em razão do interesse suscitado, decidimos ampliar a discussão em uma perspectiva nacional com a proposta deste dossiê chamado "Comunidades de pesca: pessoas, materiais, lugares e peixes".

A reflexão proposta para esta publicação partiu de diferentes questões: como identificar diferentes práticas de pesca em contextos arqueológicos? Como avaliar a importância da pesca para as comunidades do passado e do presente? Podemos estabelecer uma caracterização do "ser pescador" através do estudo da cultura material? Em todas estas questões se têm destaque para as relações materiais características de uma atividade que se desenvolve prioritariamente na água.

A pesca, em termos simplistas, é definida como o ato de retirar o peixe e outros recursos (moluscos, crustáceos, etc.) de seu ambiente aquático, mas ela também pode ser entendida como a arte ou técnica de quem pratica este ato. Nesse sentido, a nossa definição segue a proposta de Antônio Carlos Diegues (2004) de que a pesca se configura como atividade produtiva de apropriação de recursos aquáticos, que ocorre tanto em alto-mar quanto em águas abrigadas, rios e lagoas. Seguindo essa proposição, deve-se também considerar as relações históricas, sociais e culturais que se desenvolvem na prática haliêutica e dentro das comunidades pescadoras. Assim, a pesca pode ser entendida como o conjunto de práticas e saberes que se articulam entre as pessoas e os materiais em seus lugares.

Diante disso, desdobra-se o desafio de compreender as comunidades pescadoras por meio de suas relações com a água e seres aquáticos e, ao mesmo tempo, de como a materialidade torna-se uma mediadora dessas relações. Para tanto, a pesquisa arqueológica deve combinar esforços, abordando os já consagrados temas sobre o consumo de recursos aquáticos, com novas abordagens nas interpretações simbólicas dos objetos e materiais de pesca e a construção de territórios e identidades relacionados a este modo de vida e de ser.

Diante disso, este dossiê nasceu com a proposta de abrir espaço a exposição de pesquisas, independentemente de seu escopo cronológico, geográfico, sociocultural e perspectiva teórico-metodológica, buscando contribuir no desenvolvimento e a aprofundar as investigações sobre a pesca, as comunidades pescadoras, suas práticas, materiais, lugares e seres.

O dossiê inclui nove artigos inovadores com as contribuições dos mais variados campos científicos e temas que envolvem a pesca. Em linhas gerais, o presente volume traz uma diversidade de regiões e países trabalhados, contando com trabalhos do sul e sudeste do litoral do Brasil, da Amazônia, Colômbia, Venezuela e Uruguai. Diante dessa referida diversidade, apresentamos brevemente os textos:

O trabalho de Francisco Noelli traz uma discussão histórica sobre a pesca praticada pelos Guarani e seus conhecimentos ambientais através de análise de um documento do século XVII, do jesuíta Antonio Ruiz de Montoya.

Simon-Pierre Gilson e Andrea Lessa apresentam uma análise zooarqueológica do sítio pré-colonial do Rio do Meio, Santa Catarina, com uma discussão sobre a pesca, mobilidade e as relações entre grupos pescadores indígenas e tubarões.

Diana Rocio Carvajal, a partir do estudo de quatro sítios, traz à tona uma discussão sobre a pesca de populações 
indígenas da costa do Caribe Colombiano cruzando dados etno-históricos e arqueológicos.

O trabalho de Laura Beovide, a partir de uma grande síntese de dados arqueológicos, apresenta uma discussão sobre a apropriação de recursos aquáticos por populações indígenas pré-hispânicas no Rio de Prata em sua porção uruguaia.

Elis Meza discorre sobre a pesca e as relações estabelecidas entre humanos e tartarugas no Rio Orinoco, Venezuela, sob uma perspectiva diacrônica de longa duração e os possíveis efeitos da colonização neste contexto.

Jessica Ferreira e colaboradores apresentam uma síntese sobre a pesca pré-colonial de grupos indígenas na região da baía da Babitonga, em Santa Catarina, a partir de estudos arqueológicos e etnográficos com populações pescadoras tradicionais.

Soraya Martins de Alencar discute identidade e envelhecimento de pescadores a partir do estudo dos sepultamentos do sítio Mar Virado, localizado em uma ilha face ao mar aberto do litoral norte de São Paulo.

O trabalho de Gianpaolo Knoller Adomilli e colaboradores apresenta e discute os saberes e habilidades dos grupos pescadores tradicionais que envolvem a construção naval em no extremo sul do Brasil.

Por fim, Mártin César Tempass apresente um estudo etnográfico sobre a importância dos peixes e de seu consumo ritual e simbólico para os Guarani do Rio Grande do Sul.

Esperamos que este dossiê estimule novos debates acadêmicos interdisciplinares, e que apoie estudantes, pesquisadoras/es e professoras/es vinculadas/dos a avançarem no entnedimento sobre a pesca e as comunidades que vivem por meio dela.

Às autoras e autores, nossa gratidão por compartilharem seus trabalhos e o nosso desejo de que esse dossiê contribua para a divulgação e incremento de suas pesquisas. Às leitoras e leitores, a nossa aspiração de que disseminem as reflexões provocadas pelos textos e que sejam estimuladas/os a também produzirem novos conhecimentos sobre o tema partindo de suas experiências locais.

Caroline Borges

(Departamento de História, Universidade Federal Rural de Pernambuco (UFRPE), Brasil - arqueocarol@gmail.com)

Lucas Antonio da Silva

(Universidade Federal de Pelotas. Museu Nacional do Rio de Janeiro (UFPEL/MN), Brasil - las.arqueo@gmail.com)

\section{REFERÊNCIA}

DIEGUES, A. C. 2004. A pesca construindo sociedades: Leituras em antropologia marítima e pesqueira. São Paulo: Núcleo de Apoio à Pesquisa sobre Populações Humanas e Áreas Úmidas Brasileiras/USP, 315p. 